\title{
PERANCANGAN STRATEGI PEMASARAN IRT KERIPIK UBI CILEMBU CIHUY CHIPS MENGGUNAKAN SOAR STRATEGIC
}

\author{
SOAR STRATEGIC FOR MARKETING STRATEGY DESIGN \\ OF CIHUY CHIPS HOME INDUSTRY
}

\author{
Rizky Fitria Hartuti*, Dini Rochdiani \\ Universitas Padjadjaran, Jl. Raya Sumedang-Bandung, Jawa Barat 45363 \\ *Email: rizkyfitriahartuti@gmail.com \\ (Diterima 13-11-2020; Disetujui 29-12-2020)
}

\begin{abstract}
ABSTRAK
Ubi Jalar adalah salah satu komoditas tanaman pangan unggulan di Indonesia dengan total produksi 1,914,244 ton. Kabupaten Sumedang merupakan salah satu sentra produksi ubi jalar di Jawa Barat dengan produktivitas sebesar 244,84 Kw/Ha dengan varietas utama ubi cilembu. Tingkat pertumbuhan produksi dan produktivitas ubi cilembu tersebut menunjukan bahwa ubi cilembu memiliki potensi untuk dikembangkan dengan cara diolah kembali, salah satunya menjadi keripik. Salah satu industri rumah tangga yang mengolah ubi cilembu menjadi keripik adalah IRT Keripik Ubi Cilembu Cihuy Chips. Penelitian ini bertujuan untuk mengetahui strategi pemasaran yang dapat diterapkan pada IRT Keripik Ubi Cilembu Cihuy Chips. Pengumpulan data dilakukan pada bulan Juli sampai Agustus 2020 melalui observasi dan wawanca kepada informan dengan tahapan analisis SOAR. Alat analisis yang digunakan adalah diagram SOAR dan matriks SOAR. Strategi pemasaran yang dirumuskan dari matriks SOAR agar IRT Keripik Ubi Cilembu Cihuy Chips dapat bertahan serta berkembang adalah dengan memberikan potongan harga pada varian rasa bukan best seller khusus toko oleh-oleh, pengadaan varian rasa baru limited edition greentea dan cabe garam khusus Shopee, memperbaharui desain kemasan, logo dan penambahan zip lock, launching produk sistik dan eggroll dengan diskon gratis ongkir di toko online Shopee, serta promosi buy 1 get 1 pada produk yang mendekati masa kadaluarsa.
\end{abstract}

Kata kunci: Industri Rumah Tangga, Ubi Cilembu, SOAR, Strategi Pemasaran

\begin{abstract}
Sweet potatoes are one of the leading food crop commodities in Indonesia with a total production of 1,914,244 tons. Sumedang Regency is one of the sweet potato production centers in West Java with a productivity of 244.84 quintals per hectare with cilembu sweet potatoes as the main variety. The growth rate of cilembu sweet potato production and productivity shows that cilembu sweet potato has the potential to be developed by reprocessing it, one of which is into chips. One of the home industries that process cilembu sweet potato into chips product is Cihuy Chips Home Industry. This study aims to determine the marketing strategies that can be applied to Cihuy Chips Home Industry. Data collection was carried out from July to August 2020 through observations and interviews with informants using the SOAR analysis stage. The analysis tools that used are the SOAR diagram and the SOAR matrix. The marketing strategy formulated from the SOAR matrix so that the Cihuy Chips Home Industry can survive and thrive is to provide discounts on the flavor variants that are not best-sellers, procure limited edition greentea and salt chilies flavors in online store Shopee, renew the design packaging, logo and addition of zip locks, launching of cheesestick and eggroll products with free shipping fee at Shopee's online store, and buy 1 get 1 promotions on products that are nearing expiration date.
\end{abstract}

Keywords: Cilembu Sweet Potatoes, Home Industry, Marketing Strategy, SOAR 


\section{PERANCANGAN STRATEGI PEMASARAN IRT KERIPIK UBI CILEMBU CIHUY CHIPS \\ MENGGUNAKAN SOAR STRATEGIC \\ Rizky Fitria Hartuti, Dini Rochdiani}

\section{PENDAHULUAN}

Ubi jalar adalah salah satu komoditas tanaman pangan unggulan yang ada di Indonesia dengan total produksi $1,914,244$ ton (BPS 2018). Dibandingkan tahun 2017, luas panen ubi jalar tahun 2018 di Jawa Barat memiliki pertumbuhan $8,4 \%$ dan diikuti dengan kenaikan laju produksi ubi jalar tahun $2018 \quad 14,66 \%$. Laju produktivitas ubi jalar tahun 2018 pun meningkat $5,77 \%$ dibandingkan tahun 2017. Hal ini disebabkan oleh teknik budidaya yang semakin berkembang sehingga ketersediaan ubi jalar di Jawa Barat semakin meningkat dan dapat diolah lebih lanjut menjadi berbagai macam olahan.

Tabel 1. Luas Panen, Produksi, dan Produktivitas Ubi Jalar Provinsi Jawa Barat 2016-2018

\begin{tabular}{lccc}
\hline Tahun & $\begin{array}{c}\text { Luas } \\
\text { Panen } \\
(\mathrm{Ha})\end{array}$ & $\begin{array}{c}\text { Produksi } \\
(\mathrm{Kw})\end{array}$ & $\begin{array}{c}\text { Produkti- } \\
\text { vitas } \\
(\mathrm{Kw} / \mathrm{Ha})\end{array}$ \\
\hline 2016 & 23.157 & 5232.01 & 225,94 \\
2017 & 20.642 & 4778.28 & 231,48 \\
2018 & 22.377 & 5478.79 & $244 ., 84$ \\
Laju & & & \\
Pertumbuhan & & 14,66 & 5,77 \\
2018 thdp & 8,4 & & \\
$2017(\%)$ & &
\end{tabular}

Kabupaten Sumedang merupakan salah satu sentra produksi ubi jalar di Jawa Barat, dan menjadikan ubi jalar sebagai produk unggulan daerah pada Pemberdayaan Produk Unggulan Daerah Kabupaten Sumedang (Peraturan Bupati Sumedang No.9 Tahun 2018). Varietas unggul ubi jalar yang dikembangkan di Kabupaten Sumedang adalah ubi cilembu, yang telah memiliki sertifikat Indikasi Geografis yang telah terdaftar pada Direktorat Jendral HKI dan dilepas oleh pemerintah tahun 1977-2003 serta telah mendapat mendapat sertifikasi dari Keputusan Menteri Pertanian Nomor: 1224/Kpts/TP.240/2/2001 (Hoeridah dan Sarianti, 2011).

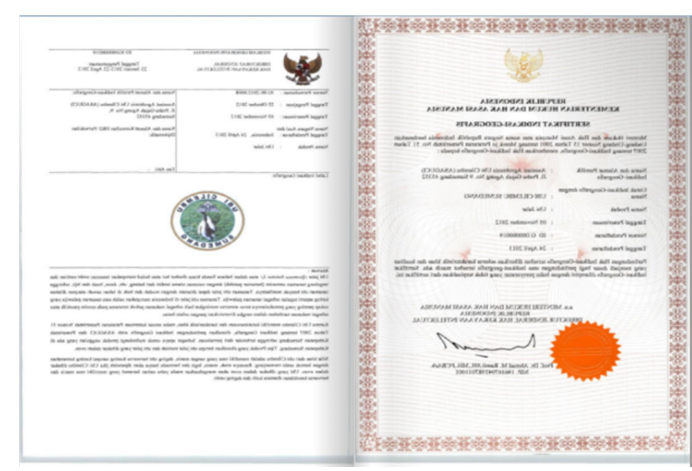

Gambar 1. Sertifikat Indikasi Geografis Ubi Cilembu

Sumber: Asosiasi Agrobisnis Ubi Cilembu (2012)

Tingkat pertumbuhan produksi, produktivitas, perlindungan hokum, serta kualitas dari ubi cilembu tersebut menunjukan bahwa ubi cilembu memiliki potensi untuk dikembangkan atau diolah kembali menjadi berbagai macam makanan untuk menambahkan nilai ekonominya. Salah satu cara pengolahan yang mudah dan banyak digemari adalah dengan mengolahnya menjadi keripik. Pengolahan ubi cilembu menjadi keripik memiliki potensi dapat meningkatkan nilai ekonomi dari ubi cilembu tersebut, dan dapat 
memanfaatkan ubi cilembu yang tidak lolos uji kualitas untuk dijual di pasaran.

Salah satu industri rumah tangga yang mengolah ubi cilembu menjadi keripik adalah Industri Rumah Tangga (IRT) Keripik Ubi Cilembu Cihuy Chips yang menciptakan inovasi poduk keripik ubi cilembu aneka rasa sebagai oleh-oleh khas Jawa Barat dengan nama "Cihuy Chips" dengan varian rasa keripik yang tersedia adalah coklat, karamel, keju original dan keju balado. Didukung dengan kemasan modern, menarik dan higienis serta memiliki izin produksi dari Departemen Kesehatan Republik Indonesia, izin produksi dari Produk Industri Rumah Tangga (P-IRT) serta mempunyai sertifikat halal dari Majelis Ulama Indonesia. Produk keripik ubi cilembu Cihuy Chips dapat ditemukan di toko oleh-oleh di Kota Bandung, Bogor dan Tangerang. IRT Keripik Ubi Cilembu Cihuy Chips juga menjual produknya secara online, melalui sosial media Instagram dan e-commerce Shopee.

IRT Keripik Ubi Cilembu Cihuy Chips ini tidak luput dari beberapa kendala yang harus dihadapi, diantaranya adalah dari segi aspek pemasarannya yang belum optimal. Berdasarkan kondisi perusahaan yang telah dipaparkan, analisis SOAR penting dilakukan pada IRT Keripik Ubi
Cilembu Cihuy Chips karena dinilai mampu melihat strategi masa depan IRT Keripik Ubi Cilembu Cihuy Chips dalam mewujudkan harapannya menjadi produk unggulan. Analisis SOAR akan berfokus pada formulasi dan implementasi dari strategi positif dengan mengidentifikasikan kekuatan, membangun kreatifitas dan peluang-peluang yang ada, meningkatkan aspirasi ataupun cita-cita perusahaan serta karyawan, dan menentukan hasil yang terukur dan bermakna baik dalam pengembangan usaha IRT Keripik Ubi Cilembu Cihuy Chips (Cole \& Stavros, 2013).

\section{METODE PENELITIAN}

Objek penelitian dalam penelitian ini adalah strategi pemasaran IRT Keripik Ubi Cilembu Cihuy Chips di Desa Cilembu, Kecamatan Pamulihan, Kabupaten Sumedang, Jawa Barat. Lokasi penelitian dipilih secara sengaja dengan pertimbangan bahwa Desa Cilembu merupakan sentra produksi ubi cilembu dengan kualitas terbaik dan terdapat IRT Keripik Ubi Cilembu Cihuy Chips yang telah menjadi produk unggulan oleh-oleh khas Jawa Barat.

Desain penelitian yang digunakan dalam penelitian ini adalah desain kualitatif. Pendekatan penelitian yang 


\section{PERANCANGAN STRATEGI PEMASARAN IRT KERIPIK UBI CILEMBU CIHUY CHIPS \\ MENGGUNAKAN SOAR STRATEGIC \\ Rizky Fitria Hartuti, Dini Rochdiani}

digunakan dalam penelitian ini menggunakan metode studi kasus dengan analisis deskriptif. Hasil data didapat dari hasil wawancara serta observasi pada saat di lapangan. Penggunaan alat analisis dari penelitian ini adalah SOAR (Strengths, Opportunities, Aspirations, Results) dimana perusahaan dapat dianalisis dari segi internal maupun eksternal. Analisis internal perusahaan dengan menggunakan analisis yang mengacu pada kekuatan (strengths) dan aspirasi (aspirations), sedangkan faktor eksternal dapat dianalisis yang mengacu pada peluang (opportunity). Setelah dilakukan semua analisis baik dari internal maupun eksternal perusahaan, maka akan dihasilkan sebuah hasil (results) dimana hasil tersebut berupa strategi untuk pemasaran keripik ubi cilembu Cihuy Chips.

Metode pengumpulan data untuk tahapan analisis SOAR dilakukan dengan wawancara kepada sampel selaku informan yaitu Chief Executive Officer, Chief Operating Officer, Chief Media Officer, Marketing Coorporate Officer, Marketing Retail Officern dan 10 orang konsumen yang sudah pernah membeli produk Cihuy Chips.

Sesuai dengan perumusan masalah, maka konsep yang akan diteliti adalah strategi pemasaran yang dilakukan IRT Keripik Ubi Cilembu Cihuy Chips yang ditinjau dari variabel-variabel sebagai berikut :

1. Strengths: kualitas produk, desain, bentuk, merek, kemasan, varian rasa, harga yang ditawarkan, lokasi penjualan, cara promosi, layanan pesanan konsumen, kondisi tempat usaha dan tampilan toko online.

2. Opportunities: informasi yang tersedia, saluran distribusi produk, harga bersaing, harga sesuai manfaat, sumber daya manusia dalam proses produksi, sumber daya manusia dalam proses penjualan, sumber daya manusia dalam manajerial, dan hubungan sosial kemasyarakatan.

3. Aspirations: aspirasi dan harapan karyawan perusahaan, aspirasi dan harapan konsumen.

4. Results: strategi pengembangan bisnis.

\section{Analisis SOAR (Strengths,}

\section{Opportunities, Aspirations, Results)}

Langkah analisis SOAR diawali dengan melakukan diskusi bersama untuk menganalisis tujuan pengembangan usaha (initiate) perusahaan menggunakan alat analisis strategi SOAR. Kemudian dilanjutkan dengan melakukan 
penyelidikan (inquiry) untuk mempelajari dan menganalisis terkait kekuatan (strength) dalam perusahaan dan peluang (opportunity) apa yang dapat dimanfaatkan. Langkah selanjutnya adalah tahap imajinasi (imagine) untuk merancang masa depan yang diharapkan berdasarkan aspirasi (aspiration) dari seluruh karyawan Tahapan selanjutnya adalah inovasi (inovate) dimana perusahaan merancang sasaran jangka pendek, rencana taktikal dan fungsional, sistem, program, dan struktur yang terintegrasi dalam usaha mencapai tujuan perusahaan di masa depan yang sesuai dengan harapan menggunakan diagram SOAR dan matriks SOAR.

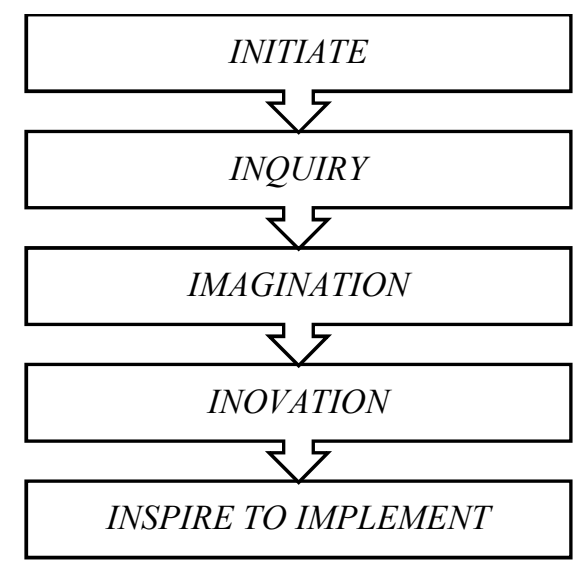

Gambar 2. Tahapan Analisis $S O A R$

Sumber: Stavros, Cooperrider and Kelley (2009)

Pada tahapan inovate, akan diidentifikasi situasi dan posisi yang dihadapi perusahaan dalam persaingan bisnis menurut faktor internal yang ada pada perusahaan dan faktor eksternal yang dihadapi oleh perusahaan. Untuk mengidentifikasi kondisi tersebut maka diperlukan diagram analisis $S O A R$.

\begin{tabular}{lcc}
\hline & Internal & Eskternal \\
\hline Presents & $\boldsymbol{S}$ & $\boldsymbol{O}$ \\
Strengths & Opportunity \\
\hline \multirow{2}{*}{ Future } & $\boldsymbol{A}$ & $\boldsymbol{R}$ \\
& Aspiration & Result \\
\hline
\end{tabular}

Gambar 3. Diagram Analisis $S O A R$

Sumber: Stavros, Cooperrider, and Kelley (2003) dalam Murni (2017).

Diagram di atas menunjukkan dua kondisi, yaitu strategic planning focus yang bersumber pada kondisi perusahaan dimana perusahaan melakukan perencanaan yang dilakukan fokus berdasarkan pada hasil tabel strengths dan opportunity. Kemudian, kondisi yang kedua yaitu human development strategy yang bersumber pada seluruh anggota perusahaan atau organisasi dimana perusahaan melakukan perencanaan yang dilakukan fokus berdasarkan pada hasil tabel aspiration dan result. Hal tersebut digambarkan dalam matriks SOAR sebagaimana tersaji pada Tabel 2 .

Tahap terakhir dari kelima proses formulasi strategi adalah pengambilan keputusan strategi terbaik yang akan diimplementasikan. 
Tabel 2. Matriks $S O A R$

$\begin{array}{rll}\text { Strategic } & \text { Strengths (S) } & \text { Opportunities } \\ \text { Inquiry } & \text { Daftarkan 5- } & \text { (O) } \\ & 10 \quad \text { kekuatan } & \text { Daftarkan 5-10 } \\ & \text { Internal disini } & \text { kekuatan } \\ & & \text { Internal disini }\end{array}$

Appreciative

Inten

\begin{tabular}{|c|c|c|}
\hline $\begin{array}{l}\text { Aspiration } \\
\text { (A) } \\
\text { Daftarkan 5- } \\
10 \text { kekuatan } \\
\text { Eksternal } \\
\text { disini }\end{array}$ & $\begin{array}{l}\text { Strategi S-A } \\
\text { Ciptakan } \\
\text { strategi yang } \\
\text { menggunakan } \\
\text { kekuatan } \\
\text { untuk } \\
\text { menciptakan } \\
\text { aspirasi }\end{array}$ & $\begin{array}{l}\text { Strategi O-A } \\
\text { Ciptakan } \\
\text { strategi } \\
\text { berorientasi } \\
\text { kepada aspirasi } \\
\text { yang } \\
\text { diharapkan } \\
\text { untuk } \\
\text { memanfaatkan } \\
\text { peluang }\end{array}$ \\
\hline $\begin{array}{l}\text { Result (R) } \\
\text { Daftarkan 5- } \\
10 \text { kekuatan } \\
\text { Eksternal } \\
\text { disini }\end{array}$ & $\begin{array}{l}\text { Strategi S-R } \\
\text { Ciptakan } \\
\text { strategi yang } \\
\text { berdasarkan } \\
\text { kekuatan } \\
\text { untuk } \\
\text { mencapai hasil } \\
\text { yang terukur }\end{array}$ & $\begin{array}{l}\text { Strategi O-R } \\
\text { Strategi yang } \\
\text { berorientasi } \\
\text { kepada } \\
\text { kesempatan } \\
\text { untuk } \\
\text { mencapai result } \\
\text { yang sudah } \\
\text { terukur }\end{array}$ \\
\hline
\end{tabular}

Sumber: Stavros (2009)

\section{HASIL DAN PEMBAHASAN}

\section{Initiate}

Tahapan awal dari langkah analisis penciptaan strategi pemasaran adalah initiate, dimana tahapan ini menjelaskan tentang apa itu analisis SOAR serta bagaimana tahapannya kepada informan yang telah ditetapkan.

\section{Inquiry}

Pada tahapan inquiry, dilakukan analisa mengenai kekuatan (strengths) dan peluang (opportunities) yang ada pada IRT Keripik Ubi Cilembu Cihuy Chips.

\section{Strengths (Kekuatan)}

1. Harga terjangkau di kalangan masyarakat.

2. Kemasan menarik dan aman.

3. Varian rasa beragam.

4. Daya simpan produk cukup lama.

5. Bahan baku yang terjamin kesegaran dan kualitasnya.

6. Pelayanan terhadap konsumen sigap dan ramah.

7. Kemudahan dalam transaksi pembelian.

8. Menjadi sponsor di berbagai acara dan kegiatan besar.

\section{Opportunities (Peluang)}

1. Perkembangan e-commerce yang pesat di Indonesia.

2. Banyaknya gerai toko oleh-oleh mitra Cihuy Chips.

3. Popularitas keripik ubi cilembu.

\section{Imagine}

Informan berkesempatan untuk memberikan aspirasi dan harapan mereka terhadap IRT Keripik Ubi Cilembu Cihuy Chips terkait dengan visi dan misi perusahaan untuk tujuan sasaran jangka panjang. 
Aspirations (Aspirasi)

1. Penambahan varian rasa baru yang lebih menarik.

2. Penambahan jenis produk olahan ubi cilembu.

3. Pembaharuan desain kemasan.

4. Peningkatan kualitas kemasan.

5. Peningkatan aktivitas media sosial.

6. Peningkatan aktivitas toko online.

7. Peningkatan gaji karyawan.

\section{Inovate}

Pada tahapan inovate, akan dipaparkan dan dikombinasikan antara aspirasi sasaran jangka pendek dan apirasi sasaran jangka panjang serta hasil (result) yang terukur pada IRT Keripik Ubi Cilembu Cihuy Chips agar diagram dan matriks $S O A R$ dapat terisi sehingga dapat tercipta strategi pemasaran yang tepat bagi IRT Keripik Ubi Cilembu Cihuy Chips.

\section{Results (Hasil)}

1. Menambahkan varian rasa seperti greentea dan cabe garam.

2. Mengganti komposisi desain, seperti perubahan logo dan tata letak tulisan.

3. Menambahkan zip lock pada kemasan.

4. Melakukan promosi yang lebih pada sosial media, serta memberikan promo potongan harga menarik dan menggunakan jasa paid promote atau endorsment.

5. Meningkatkan aktivitas toko online dengan menggunakan fitur iklan berbayar dan fitur Shopee Seller Center.

6. Meningkatkan gaji karyawan untuk mendorong kinerja karyawan dan memberikan kenyamaan kerja bagi karyawan.

Berdasarkan hasil pemaparan pada diagram $S O A R$, terdapat dua kondisi pada IRT Keripik Ubi Cilembu Cihuy Chips. (1) Strategic planning focus dimana berdasarkan kekuatan (strength) dan peluang (opportunity) yang telah dianalisis, dapat disimpulkan bahwa IRT Keripik Ubi Cilembu Cihuy Chips saat ini dapat memanfaatkan peluang yang ada dengan mempertahankan kekuatan perusahaan. (2) Human development strategy bahwa IRT Keripik Ubi Cilembu Cihuy Chips dapat menerapkan aspirasi yang disampaikan oleh seluruh karyawan.

Setelah mendapatkan gambaran kondisi perusahaan dari strategi yang diciptakan menggunakan diagram SOAR tersebut, maka tahapan selanjutnya adalah melakukan analisis dengan menggunakan matriks SOAR. Matriks SOAR akan diisi dengan aspek kekuatan (strength), peluang (opportunity), aspirasi 


\section{PERANCANGAN STRATEGI PEMASARAN IRT KERIPIK UBI CILEMBU CIHUY CHIPS \\ MENGGUNAKAN SOAR STRATEGIC \\ Rizky Fitria Hartuti, Dini Rochdiani}

(aspiration) dan hasil (result) yang berasal dari wawancara serta diskusi dengan informan. Setelah semua bagian pada matriks SOAR terisi, maka akan dirumuskan strategi pemasaran berdasarkan rumus Strength-Aspiration,
Opportunity-Aspiration, Strength-Result, dan Opportunity-Result yang sudah tersaji dan dirumuskan alternatif strategi apa saja yang dapat digunakan serta diterapkan oleh IRT Keripik Ubi Cilembu Cihuy Chips.

Tabel 2. Matriks $S O A R$

Strategic Inquiry (Internal) S (Strength)

1. Harga yang terjangkau di kalangan masyarakat.

2. Kemasan dengan desain menarik dan kualitas baik.

3. Varian rasa yang beragam (coklat, karamel, keju original, keju balado).

4. Daya simpan produk cukup lama.

5. Bahan baku yang terjamin kesegaran dan kualitasnya.

6. Pelayanan terhadap konsumen yang sigap dan ramah.

7. Kemudahan dalam pembelian melalui toko offline maupun toko online.

8. Menjadi sponsor di berbagai acara dan kegiatan besar.

\section{Appreciative Intent (Eksternal)}

A (Aspiration)

1. Penambahan varian rasa baru.

2. Penambahan jenis produk olahan ubi cilembu.

3. Pembaharuan desain kemasan.

4. Pembaharuan kualitas kemasan.

5. Promosi yang lebih terutama pada media sosial.

6. Promo potongan harga atau diskon pada momen tertentu.

7. Peningkatan aktivitas toko online di Shopee.

8. Peningkatan gaji karyawan.

\section{Strategi S-A}

- Memberikan diskon potongan harga pada varian rasa bukan best seller khusus toko oleh-oleh. (S1, S3, S7, A5, A6)

- Launching produk olahan ubi cilembu jenis baru pada perayaan ulang tahun Cihuy Chips. (S5,S7,A2, A5)

- Promosi buy 1 get 1 pada produk yang mendekati masa kadaluarsa. (S1, S4, A5, A6, A7)

- Launching desain kemasan baru dan penambahan zip lock pada perayaan tahun baru. (S2, S4, A3, A4, A5)

- Melakukan training karyawan dan toko oleh-oleh mitra Cihuy Chips agar lebih mengetahui informasi produk. (S5, S6, S7, A7)

- Promosi potongan harga untuk panitia acara/kegiatan yang disponsori oleh Cihuy Chips. (S1, S6, S8, A6)

\section{O (Opportunity)}

1. Perkembangan e-commerce yang pesat di Indonesia memudahkan penjualan melalui toko online.

2. Banyaknya gerai toko oleholeh mitra Cihuy Chips.

3. Popularitas keripik ubi cilembu yang sedang naik di kalangan masyarakat.

\section{Strategi O-A}

- Promosi potongan harga dalam rangka pembukaan toko online baru di Tokopedia. (O1, A6)

- Produk limited edition dengan desain batik Jawa Barat pada hari ulang tahun Jawa Barat. (O2, A3, A5)

- Membuat paket Holiday Bundle Pack saat musim liburan. (O2, O3, A5, A6).

- Membuat IGTV proses produksi keripik ubi cilembu Cihuy Chips. (A5, O3) 
Tabel 2. Matriks SOAR (Lanjutan)

\section{R (Result) Strategi S-R}

1. Menambahkan varian rasa seperti greentea dan cabe garam.

2. Menambahkan produk sistik ubi cilembu dan eggroll ubi cilembu.

3. Mengganti komposisi desain, seperti perubahan logo dan tata letak tulisan.

4. Menambahkan zip lock pada kemasan.

5. Melakukan promosi yang lebih pada sosial media, serta memberikan promo potongan harga menarik dan menggunakan jasa paid promote atau endorsment.

6. Meningkatkan aktivitas toko online dengan menggunakan fitur iklan berbayar dan fitur Shopee Seller Center.

7. Meningkatkan gaji karyawan untuk mendorong kinerja karyawan dan memberikan kenyamaan kerja bagi karyawan.
- Promosi diskon 20\% untuk varian rasa baru greentea dan cabe garam khusus Shopee. (S1, S3, S7, R1, R6)

- Memperbaharui desain kemasan, logo dan penambahan zip lock. (S2, $\mathrm{S} 3, \mathrm{~S} 4, \mathrm{R} 3, \mathrm{R} 4)$

- Launching produk sistik dan eggroll dengan diskon gratis ongkir di toko online Shopee. (S1, S6, S7, R2, R6)

- Melakukan promosi terkait kemudahan dalam pembelian melalui toko offline maupun toko online dengan jasa paid promote atau endorsment. (S2, S7, R5)

- Meningkatkan pelayanan yang sigap dan ramah dengan menggunakan fitur Shopee Seller Center. (S6, S7, R6)

- Meningkatkan gaji karyawan untuk mendorong kinerja karyawan untuk memberikan pelayanan yang sigap dan ramah serta memberikan kenyamaan kerja bagi karyawan.(S6, R7)

\section{Strategi O-R}

- Varian rasa greentea dan cabe garam limited edition saat memasuki musim liburan. (O1, O2, O3, R1, R5)

- Memperbaharui kemasan dengan menambahkan zip lock dan informasi manfaat ubi cilembu pada desain kemasan. (O3, R3, R4)

- Melakukan promosi yang lebih pada sosial media menggunakan jasa paid promote atau endorsment pada saat musim liburan tiba. (O2, O3, R5)

- Memberikan promo potongan ongkos kirim untuk konsumen yang berada di luar pulau Jawa pada pembelian di toko online. (O1, R5, R6)
Setelah selesai dengan pemaparan yang telah dilakukan mengenai beberapa strategi pemasaran yang diciptakan dari diagram dan matriks SOAR, maka dirumuskan alternatif strategi apa saja yang dapat digunakan serta diterapkan oleh IRT Keripik Ubi Cilembu Cihuy Chips demi keberlangsungan usaha diantaranya ialah:

1. Strategi memberikan diskon potongan harga pada varian rasa bukan best seller khusus toko oleh-oleh.

2. Strategi varian rasa baru limited edition greentea dan cabe garam khusus Shopee.
3. Strategi memperbaharui desain kemasan, logo dan penambahan zip lock.

4. Strategi launching produk sistik dan eggroll dengan diskon gratis ongkir di toko online Shopee.

5. Strategi promosi buy 1 get 1 pada produk yang mendekati masa kadaluarsa.

\section{Inspire to Implement}

Rancangan strategi pemasaran yang sudah tercipta diserahkan kepada seluruh karyawan IRT Keripik Ubi Cilembu Cihuy Chips untuk dipahami lebih dalam 
dan dipelajari dengan tujuan seluruh karyawan IRT Keripik Ubi Cilembu Cihuy Chips paham akan strategi pemasaran yang telah dirancang tersebut sehingga akan tercipta hasil yang terukur baik dalam jangka pendek maupun jangka panjang pada IRT Keripik Ubi Cilembu Cihuy Chips.

\section{KESIMPULAN DAN SARAN}

\section{Kesimpulan}

Berdasarkan hasil analisis SOAR, strategi pemasaran yang dapat dijadikan rumusan strategi serta dapat diimplementasikan pada IRT Keripik Ubi Cilembu Cihuy Chips adalah strategi memberikan diskon potongan harga pada varian rasa bukan best seller khusus toko oleh-oleh, strategi varian rasa baru limited edition greentea dan cabe garam khusus Shopee, strategi memperbaharui desain kemasan, logo dan penambahan zip lock, strategi launching produk sistik dan eggroll dengan diskon gratis ongkir di toko online Shopee, strategi promosi buy 1 get 1 pada produk yang mendekati masa kadaluarsa.

\section{Saran}

Berdasarkan penelitian yang sudah dilakukan mengenai penyusunan strategi pemasaran pada IRT Keripik Ubi
Cilembu Cihuy Chips berdasarkan analisis kekuatan (strength), peluang (opportunity), aspirasi (aspiration), dan hasil (result), IRT Keripik Ubi Cilembu Cihuy Chips disarankan menerapkan strategi pemasaran yang telah dirumuskan.

\section{DAFTAR PUSTAKA}

Adi Saputro, R. and Suranto, I. (2020). Strategi Pengembangan Pemasaran Menggunakan Analisis SOAR (Strenght, Opportunity, Aspiration, Result) Dan Matrik QSPM (Studi Kasus: Karamba Jaring Apung Ikan Nila) Doctoral dissertation, Universitas Muhammadiyah Surakarta.

Arman, A., \& Nugraha, N. (2020). Perancangan Strategi Pemasaran Produk Tas Kulit di Kota Bandung dengan Menggunakan Metode Importance Performance Analysis (IPA) dan Strengths, Opportunities, Aspirations, Results (SOAR). Universitas Islam Bandung.

Chiu, Calvin. (2018). Analisis Strategi SOAR PT.XYZ Dalam Meningkatkan Penjualan Bahan Baku Kimia Untuk Industri Tekstil, Kayu, Pakaian dan Detergen. Program Studi Magister Manajemen Universitas Tarumanagara. Jakarta.

BPS. (2018). Badan Pusat Statistik. https://bps.go.id/site/resultTab. [20 Oktober 2020].

David, F.R (2010). Strategic Management. Manajemen Strategis Edisi Keduabelas. Buku Satu. Salemba Empat. Jakarta. 
Hoeridah, A., \& Sarianti, T. (2011). Analisis Daya Saing Ubi Jalar Cilembu di Kabupaten Sumedang Jawa Barat. Fakultas Ekonomi dan Manajemen Institut Pertanian Bogor. Bogor.

Kotler, Philip dan Kevin Lane Keller. (2016). Marketing Managemen, $15^{\text {th }}$ Edition. Pearson Education, Inc.

Kotler, Philip dan Gary Amstrong. (2012). Principles Of Marketing $14^{\text {th }}$ Edition. Prentice-Hall Published. New Jersey.

Rangkuti, Freddy. (2006). Teknik Mengukur dan Strategi Meningkatkan Kepuasan. Pelanggan. Penerbit PT Gramedia Pustaka Utama. Jakarta.

Stavros, J.M., Cooperrider, D. \& Kelley, L. (2009). Strategic Inquiry With Appreciative Intent: Inspiration to SOAR! Al Practitioner: International
Journal of Appreciative Inquiry, Vol. 5 No.4.

Stavros, J.M. \& Cole, M.L. (2013). Soaring Toward Positive Transformation and Change. The ABAC ODI Visions. Action. Outcome, Vol. 1 No.1.

Sugiarti, W. S. (2017). Analisis Strategi Pemasaran Produk Usaha Mikro Kecil Menengah Melalui Metode Analisis Soar (Strength, Opportunity, Aspirations, Result) Studi pada UMKM Kue Cubit Laina Di Medan. Universitas Sumatera Utara.

Zamista, A. A., \& Hanafi, H. (2020). Analisis SOAR pada Strategi Pemasaran di Industri Jasa Finance. Jurnal Teknik Industri: Jurnal Hasil Penelitian dan Karya Ilmiah dalam Bidang Teknik Industri, 6(1), 27-33. 